\title{
Novel Dual Acting Antimalarial Antileishmanial Agents Derived from Pyrazole Moiety
}

\author{
Adnan A. Bekhit 1,*iD, Sherry N. Nasralla ${ }^{2}$ (D), Salma A. Bekhit ${ }^{3}$ (D), Alaa El-Din A. Bekhit ${ }^{4}$ (D) \\ 1 Department of Pharmaceutical Chemistry, Faculty of Pharmacy, Alexandria University, Alexandria 21521, Egypt; \\ adnbekhit@pharmacy.alexu.edu.eg (A.A.B.); \\ 2 Pharmacy Program, Allied Health Department, College of Health and Sport Sciences, University of Bahrain, P.O. Box \\ 32038, Kingdom of Bahrain; snasralla@uob.edu.bh (S.N.N.); \\ 3 High Institute of Public Health, Alexandria University, Alexandria 21568, Egypt; salma2010@alexu.edu.eg (S.A.B.); \\ 4 Food Sciences, University of Otago, Dunedin, New Zealand; aladin.bekhit@otago.ac.nz (A.E.-D.A.B.); \\ * Correspondence: adnbekhit@ pharmacy.alexu.edu.eg (A.A.B);
}

Scopus Author ID: 7003826784

Received: 8.07.2021; Revised: 20.09.2021; Accepted: 24.09.2021; Published: 8.11.2021

\begin{abstract}
Malaria and leishmaniasis are two highly detrimental parasitic diseases with a global impact. Attempts to eradicate malaria and control leishmaniasis are generally unsuccessful due to the rapidly developing resistance to currently used drug therapy. The pyrazole ring is a key moiety reported to have a variety of biological activities. The current study aimed to design, synthesize and evaluate an array of pyrazole derivatives for potential antimalarial antileishmanial activity. The scheme for the synthesis of the pyrazole derivatives is presented. The antimalarial activity was assessed in-vivo on P. berghei ANKA infected mice to determine \% parasitemia and mean survival time. The antileishmanial activity was assessed in-vitro, and $\mathrm{IC}_{50}$ for each compound was calculated. In-vivo acute toxicity and molecular docking on putative antimalarial and antileishmanial drug targets were performed using the most active compounds. All the derivatives exhibited significant antimalarial activity, the highest being 95\% suppression of parasitemia with compounds $9 \mathrm{a}$ and $9 \mathrm{~b}$. The mean survival time of mice treated with these two compounds was also the highest (16-17 days) but was lower than chloroquine, the standard agent. Compounds $9 \mathrm{a}$ and $9 \mathrm{~b}$ exhibited superior antileishmanial activity as compared to miltefosine. However, they were less potent than amphotericin. The compounds were safe and well-tolerated at toxic, oral and intraperitoneal, doses of $150 \mathrm{mg} / \mathrm{kg}$ and $75 \mathrm{mg} / \mathrm{kg}$, respectively. Molecular docking of compound 9a revealed a good fitting pose with plasmodial Pf-DHFR enzyme and Lm-PTR1 enzyme, which explains the biological activity noted with this compound. Pyrazole derivatives $9 \mathrm{a}$ and $9 \mathrm{~b}$ exhibited substantial dual antimalarial antileishmanial activity and may be a valuable scaffold for the design of further derivatives with antiprotozoal potential.
\end{abstract}

Keywords: pyrazole; antimalarial; antileishmanial; plasmodial $P f$-DHFR enzyme and $L m$-PTR1 enzyme

(C) 2021 by the authors. This article is an open-access article distributed under the terms and conditions of the Creative Commons Attribution (CC BY) license (https://creativecommons.org/licenses/by/4.0/).

\section{Introduction}

Malaria and leishmaniasis are detrimental protozoal diseases posing a great burden to many countries in Africa, Asia, South America, and Europe [1,2]. Four species of the genus Plasmodium cause malaria; however, most infections are caused by Plasmodium falciparum and Plasmodium vivax. Leishmaniasis is considered one of the neglected tropical diseases (NTDs) and is caused by over twenty species of the genus Leishmania, with symptoms varying from the more common cutaneous lesions to fatal visceral disease [3]. 
Despite the many interventions implemented to control the spread of these diseases, malaria accounted for 229 million cases globally in twenty-nine countries in the year 2019, with almost $50 \%$ of the cases reported within the African continent [1]. Additionally, almost 700,000 to one million Leishmania infections are estimated globally every year ${ }^{2}$.

The rapidly developing resistance to the currently available treatment regimens and the adverse effects associated with antimalarial therapy are obstacles to eradicating malaria [3-6]. Furthermore, the chemotherapeutic options for leishmaniasis are associated with high cost, lengthy regimens with high side effects, and declining therapeutic efficacy [3,7-9]. Thus, the search for new effective antimalarial and antileishmanial agents is becoming necessary to control these diseases and retard their health, social and economic burdens.

Despite multiple mutations, the dihydrofolate reductase (DHFR) enzyme continues to be a putative target of new antimalarial agents due to its ability to prevent DNA synthesis and cell proliferation, thereby resulting in the death of the protozoal cell [10-13]. In Leishmania species, a target enzyme is the pteridine reductase enzyme (PTR1), which protects the parasite against oxidative stress and its critical role in cell growth by reducing folate and biopterin to tetrahydrofolate and tetrahydrobiopterin, respectively [14-17]. The pyrazole ring is a structure of key importance due to its reported antibacterial, antiviral, antitubercular, anti-inflammatory, analgesic, anticancer and antileishmanial activities [18-25]. This study aims to design, synthesize, and evaluate a number of pyrazole derivatives as potential antimalarial antileishmanial agents. Acute toxicity of active compounds and molecular docking within putative targets; DHFR and PTR1 enzymes are also explored.

\section{Materials and Methods}

\subsection{Chemistry.}

Reactions for the synthesis of intermediate and target compounds were performed as illustrated in Figure 1. 3-aryl-1-phenyl- $1 H$-pyrazole-4-carboxaldehyde 1a,b was condensed with hydroxylamine hydrochloride in ethanol containing anhydrous sodium acetate, resulting in a good yield of the intermediates 1-Aryl-3-phenyl- $1 H$-pyrazole-4-aldoxime 2a,b. The oximes $\mathbf{2 a}, \mathbf{b}$ were dehydrated with acetic anhydride giving rise to the cyano derivatives $\mathbf{3 a}, \mathbf{b}$, which underwent cyclization with cysteamine hydrochloride in the presence of sodium hydroxide leading to the formation of the thiazolidine derivatives $\mathbf{4 a , b}$. Aldehydes 1a,b were condensed with 4-fluorobenzylamine, which led to the formation of Schiff's bases $\mathbf{5 a}, \mathbf{b}$, which further reacted with thioglycolic acid in the presence of anhydrous zinc chloride, to give thiazolidinone derivatives $\mathbf{6 a , b}$. The pyrazole carboxaldehyde 1a,b was reacted with Lcysteine, in the presence of DCC/HOBt, followed by $\mathrm{N}$-protection using $(\mathrm{Boc})_{2} \mathrm{O}$, thus resulting in compounds $\mathbf{7 a}, \mathbf{b}$. Compounds, $\mathbf{7 a , b}$, were subsequently subjected to either of two reactions; the first being $\mathrm{N}$-deprotection using $4 \mathrm{~N} \mathrm{HCl} /$ dioxane, leading to the formation of thiazolidine carboxylic acid derivatives 10a,b. Alternatively, compounds 7a,b were reacted with $\mathrm{NH}_{4} \mathrm{OH}$ in the presence of $\mathrm{DCC} / \mathrm{HOBt}$, resulting in the corresponding carboxamide derivatives $\mathbf{8 a}, \mathbf{b}$, which were subjected to $\mathrm{N}$-deprotection, to form carboxamide derivatives 9a,b. 


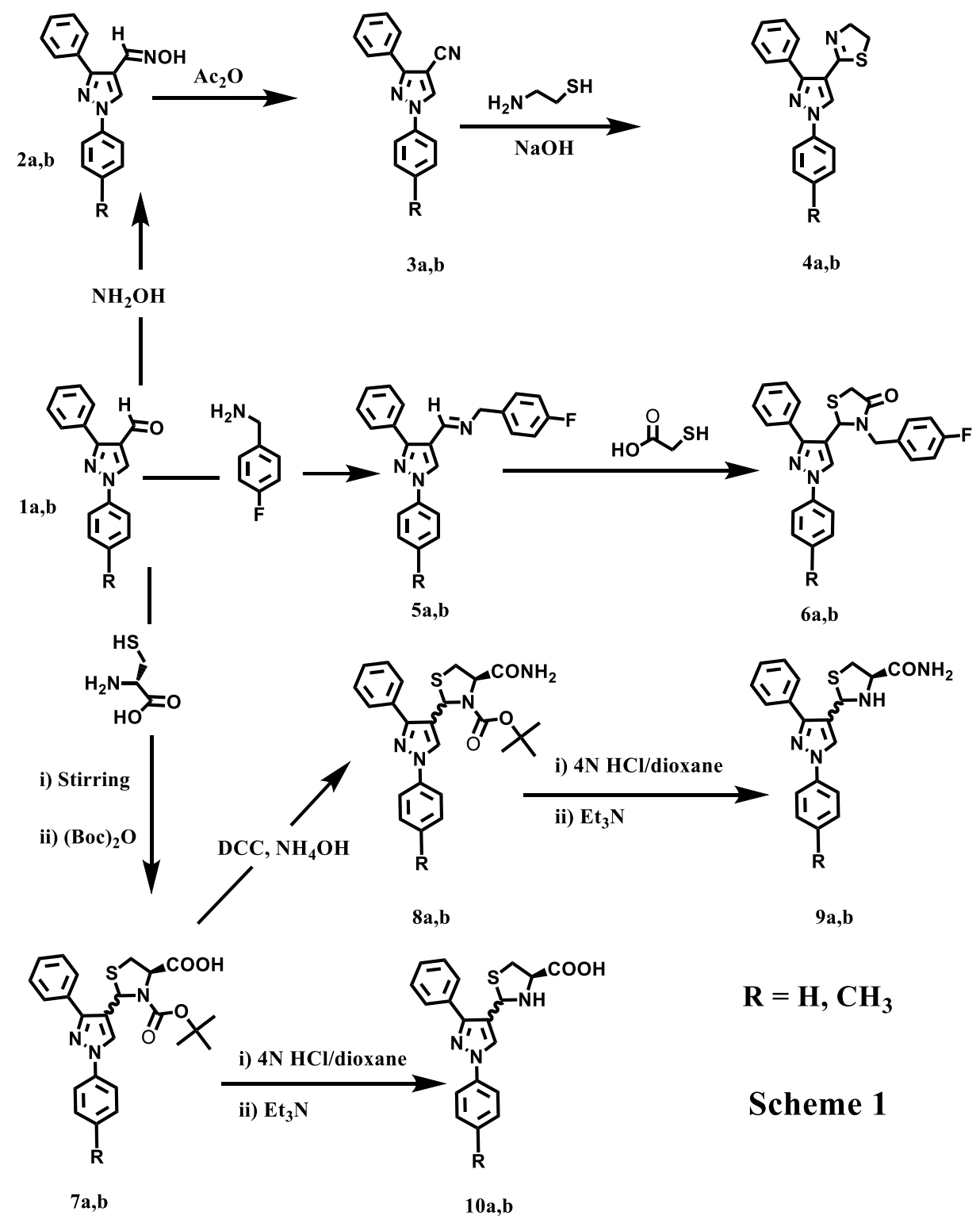

Figure 1. Synthesis of the target compounds.

\subsection{Biological screening.}

\subsubsection{In-vivo antimalarial activity.}

The antimalarial activity of the synthesized compounds was tested in-vivo using a modified 4-day standard suppressive test as described by Fidok et al. [26]. This preliminary test assesses the efficacy of compounds by comparing the blood parasitemia levels and survival times in treated and untreated mice.

Test mice were injected with $0.2 \mathrm{ml}$ of $2 \times 10^{7}$ parasitized erythrocytes $(\underline{P} . \underline{\text { berghei }}$ ANKA strain) intravenously on day 0. Two hours later, the infected mice were weighed and divided randomly into groups of six mice, with a total of ten groups. In groups $1-8$, the synthesized compounds were administered orally at $50 \mu \mathrm{mol} / \mathrm{kg}$ dose levels, serving as treatment groups. Mice in group 9 received the vehicle (7\% Tween 80,3\% ethanol in distilled water), serving as a negative control. Mice in group 10 received the standard agent chloroquine phosphate (CQ, Sigma-Aldrich, Deisenhofen, Germany) at the same dose level $(50 \mu \mathrm{mol} / \mathrm{kg})$, thus serving as a positive control. On the following days, 1 to 3 , mice from the experimental groups were treated daily with the same dose and route of each synthesized compound. Blood 
smears from all test mice were collected on day 4 and prepared using Giemsa stain. Parasitemia levels were determined microscopically by counting 4 fields, each containing approximately 100 erythrocytes. Percent suppression of activity was calculated as the difference between the mean value for the negative control group (taken as 100\%) and the experimental groups.

$\%$ Parasitemia $=\frac{\text { Number of infected RBCs }}{\text { Total number of RBCs }} X 100$

$\%$ Suppression $=\frac{\text { Parasitemia in negative control }- \text { Parasitemia in treatment group }}{\text { Parasitemia in the negative control }} X 100$

The survival time for each test mouse was recorded, then the mean survival time was calculated in days. These times were then compared to those of the negative control group, as untreated mice typically die approximately one week after infection. Conversely, the survival time for chloroquine-treated mice was not recorded since they were completely cured of the parasite.

\subsubsection{In-vitro antileishmanial activity.}

A 3-day-old culture of Leishmania aethiopica promastigotes was used, with adjustment of promastigote count to $3 \times 10^{6} / \mathrm{ml}$. $100 \mu \mathrm{L}$ of the culture were introduced per weel of a 96well plate (Nunc, Denmark), and six different concentrations of the test compounds were then added in triplicates. Plates were incubated for 24 hours. Microscopic monitoring for viability and motility of parasitic cells was done by using Alamar blue colorimetric assay [27]. Miltefosine and amphotericin B deoxycholate were used as antileishmanial control drugs. Inhibitory concentration ( $\mathrm{IC}_{50}$ ) of the test compounds and standard drugs in $\mu \mathrm{g} / \mathrm{ml}$ was determined.

\subsubsection{In-vivo acute toxicity testing.}

Compounds showing promising antimalarial antileishmanial activity were selected for in-vivo acute toxicity testing. The male mice weighing $26-32 \mathrm{~g}$ each were divided into groups of six, fasted overnight, and weighed before the test [28]. Suspensions of the test compounds in an aqueous vehicle containing $1 \%$ gum acacia were prepared. Doses of 25, 50, 100, and $150 \mathrm{mg} / \mathrm{kg} /$ day of the synthesized compounds were administered to the mice orally, while the control group received the vehicle at a maximum dose of $1 \mathrm{ml} / 100 \mathrm{~g}$ of body weight orally $[29,30]$. Acute parenteral toxicity of the test compounds was also assessed in groups of six mice, each as reported earlier. Intraperitoneal injection of either the compounds or the vehicle, propylene glycol (control), was done daily in doses of 10, 25, 50, and 75mg/kg. Mice were observed for any signs of acute toxicity for one week [31].

\subsubsection{Molecular docking study.}

Molecular docking was performed using Molecular Operating Environment (MOEDock 2008) software [32]. The protein data bank was used to download the structures of Plasmodium falciparum dihydrofolate reductase ( $P f$-DHFR) enzyme (PDB ID: 1J3I) and Leishmania major pteridine reductase (Lm-PTR1) enzyme (PDB ID: 2BFM). Target compounds were also constructed, and active sites were generated using the MOE-Alpha Site Finder. Test compounds with the highest biological activity were docked into the enzyme's active site, and the conformer with the highest score was selected for each compound. 


\section{Results and Discussion}

Derivatives of the pyrazole ring were synthesized and biologically evaluated for antimalarial and antileishmanial activity. The target derivatives synthesized in Figure 1 were obtained in sufficient yield and purity following the procedure of Fargaly et al. [33]. The chemical structures of the synthesized compounds were confirmed by IR, NMR, and microanalyses. It is worthy of mention that all attempts to separate diastereomers of compounds 7, 8, 9, and 10 were unfruitful. 2,4-disubstituted thiazolidines cis and trans diastereomers interconverted freely in solution [31,34].

The in-vivo antimalarial testing revealed that all target compounds showed significant antimalarial activity, with a minimum of 59.3\% suppression compared to chloroquine, reported with compound $\mathbf{6 a}$. Compounds $\mathbf{9 a}$ and $\mathbf{9 b}$ showed the highest \% suppression of $95.35 \%$ and $96.51 \%$, respectively, which was comparable to positive chloroquine control, indicating promising antimalarial activity (Table 1). The lowest mean survival time among treated groups was 8.4 days reported with compound $\mathbf{4 b}$, which was higher than 5.24 days observed in the negative control group. Conversely, compounds $9 \mathbf{a}$ and $9 \mathbf{b}$ showed a mean survival time of 17.6 and 16.22 days, respectively. Although this was less than the positive control (where no death was reported over the experimental period), it was the highest among the studied compounds (Table 1).

Table 1. In-vivo antimalarial activity of tested compounds.

\begin{tabular}{c|c|c|c|c} 
Compound number & $\mathbf{R}$ & $\boldsymbol{\%}$ Parasitemia* & \% Suppression & $\begin{array}{c}\text { Mean Survival } \\
\text { Time (days) }\end{array}$ \\
\hline $4 \mathrm{a}$ & $\mathrm{H}$ & $\mathbf{3 3} \pm \mathbf{0 . 4}$ & $\mathbf{6 1 . 6 2}$ & $\mathbf{8 . 6 2}$ \\
\hline $4 \mathrm{~b}$ & $\mathrm{CH}_{3}$ & $\mathbf{3 0} \pm \mathbf{0 . 8}$ & $\mathbf{6 5 . 1 1}$ & $\mathbf{8 . 4 0}$ \\
\hline 6a & $\mathrm{H}$ & $\mathbf{3 5} \pm \mathbf{0 . 8}$ & $\mathbf{5 9 . 3 0}$ & $\mathbf{8 . 7 1}$ \\
\hline 6b & $\mathrm{CH}_{3}$ & $\mathbf{2 6} \pm \mathbf{1 . 6}$ & $\mathbf{6 9 . 7 7}$ & $\mathbf{1 1 . 6 0}$ \\
\hline 9a & $\mathrm{H}$ & $\mathbf{4} \pm \mathbf{0 . 4}$ & $\mathbf{9 5 . 3 5}$ & $\mathbf{1 7 . 6 0}$ \\
\hline 9b & $\mathrm{CH}_{3}$ & $\mathbf{3} \pm \mathbf{0 . 2}$ & $\mathbf{9 6 . 5 1}$ & $\mathbf{1 6 . 2 2}$ \\
\hline $10 \mathrm{a}$ & $\mathrm{H}$ & $\mathbf{2 6} \pm \mathbf{1 . 2}$ & $\mathbf{6 9 . 7 7}$ & $\mathbf{1 0 . 8 2}$ \\
\hline $10 \mathrm{~b}$ & $\mathrm{CH}_{3}$ & $\mathbf{2 2} \pm \mathbf{1 . 6}$ & $\mathbf{7 4 . 4 2}$ & $\mathbf{1 0 . 6 4}$ \\
\hline NC & - & $\mathbf{8 6} \pm \mathbf{1 . 2}$ & $\mathbf{0 . 0 0}$ & $\mathbf{5 . 2 4}$ \\
\hline Chloroquine phosphate & - & $\mathbf{0 . 0}$ & $\mathbf{1 0 0}$ & ND
\end{tabular}

NC: Negative control, ND: No death recorded over the experimental period

With regards to the in-vitro antipromastigote test, results revealed that compounds $\mathbf{4 a}$, 4b, 9a, 9b, 10a, and 10b had higher antileishmanial activities than miltefosine, while the activity of compounds $\mathbf{6 a}$ and $\mathbf{6 b}$ was lower compared to the same. All target compounds exhibited lower activity compared to amphotericin B deoxycholate standard drug. The most active compounds were $\mathbf{4 a}, \mathbf{4 b}, \mathbf{9 a}$, and $\mathbf{9 b}$. However, the highest activity reported was for compounds 9a and 9b with $\mathrm{IC}_{50}$ values of $1.028 \mu \mathrm{g} / \mathrm{ml}$ and $1.083 \mu \mathrm{g} / \mathrm{ml}$, respectively (Table 2). It is thus worth mentioning that compounds $9 \mathbf{a}$ and $\mathbf{9 b}$ showed the highest dually acting antileishmanial antimalarial activity.

Table 2. Antileishmanial (antipromastigote) activity ( $\left.\mathrm{IC}_{50}\right)$ of the test compounds in $\mu \mathrm{g} / \mathrm{ml}$.

\begin{tabular}{c|c|c} 
Compound number & $\mathbf{R}$ & IC $_{\mathbf{5 0}}$ \\
\hline $4 \mathrm{a}$ & $\mathrm{H}$ & $\mathbf{1 . 6 6 2 2}$ \\
\hline $4 \mathrm{~b}$ & $\mathrm{CH}_{3}$ & $\mathbf{1 . 1 1 2 4}$ \\
\hline $6 \mathrm{a}$ & $\mathrm{H}$ & $\mathbf{4 . 8 4 1 2}$ \\
\hline $6 \mathrm{~b}$ & $\mathrm{CH}_{3}$ & $\mathbf{4 . 0 0 1 1}$ \\
\hline $9 \mathrm{a}$ & $\mathrm{H}$ & $\mathbf{1 . 0 2 8 8}$
\end{tabular}




\begin{tabular}{c|c|c} 
Compound number & R & IC50 \\
\hline $9 \mathrm{~b}$ & $\mathrm{CH}_{3}$ & $\mathbf{1 . 0 8 3 1}$ \\
\hline $10 \mathrm{a}$ & $\mathrm{H}$ & $\mathbf{3 . 0 8 8 2}$ \\
\hline $10 \mathrm{~b}$ & $\mathrm{CH}_{3}$ & $\mathbf{2 . 9 1 4 2}$ \\
\hline Miltefosine & - & $\mathbf{3 . 1 9 2 1}$ \\
\hline Amphotericin B deoxycholate & - & $\mathbf{0 . 0 4 7 2}$
\end{tabular}

In-vivo acute toxicity studies in experimental mice were performed on compounds $\mathbf{4 a}$, 4b, 9a, and 9b, since they exhibited the highest antiprotozoal activities in the biological screening phase. Results revealed no signs of acute toxicity following treatment with daily, intraperitoneal and oral doses of $75 \mathrm{mg} / \mathrm{kg}$ and $150 \mathrm{mg} / \mathrm{kg}$, respectively. There were also no significant changes in the weights of experimental mice, and no deaths were reported 7 days following the daily administration of toxic doses of the target compounds. It was thus safe to conclude that the test compounds were well-tolerated and non-toxic to the experimental animals both orally (in doses up to $150 \mathrm{mg} / \mathrm{kg}$ ) and parenterally (in doses up to $75 \mathrm{mg} / \mathrm{kg}$ ).

Compound 9a, exhibiting one of the highest antimalarial antileishmanial dual activity, was selected for molecular docking in the $P f$-DHFR and $L m$-PTR 1 enzymes as potential targets within Plasmodia and Leishmania species, respectively. Docking's study revealed that there was good interaction between the backbone of the $P f$-DHFR enzyme and compound 9a.

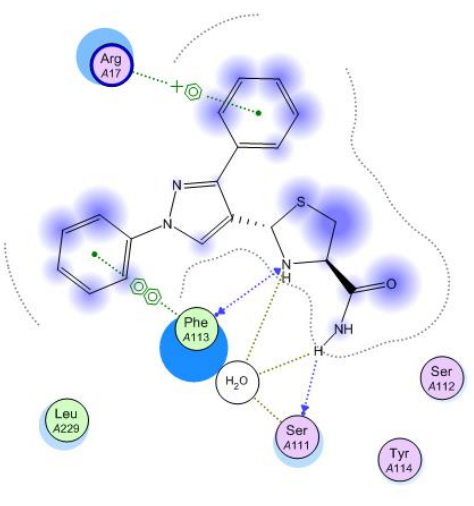

Figure 2. 2D view from molecular docking study of the minimum-energy structure of the complex of 9a docked in $P f$-DHFR (PDB ID:1J3I) viewed using MOE module.

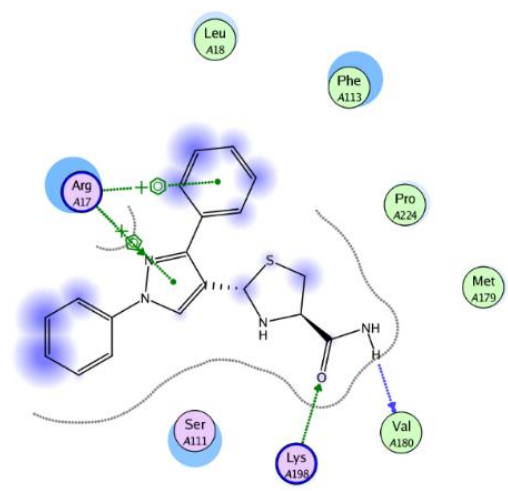

Figure 3. 2D view from molecular docking study of the minimum-energy structure of the complex of 9a docked in Lm-PTR1 (PDB ID:2BFM) viewed using MOE module.

Figure 2 shows hydrophobic interactions in addition to hydrogen bonding between the compound's thiazolidine $\mathrm{NH}$ and Phe A113 residue, as well as hydrogen bonding between amidic NH of the compound and Ser A111 residue of the enzyme. Furthermore, upon docking the compound in Lm-PTR1, the study revealed hydrophobic interactions between the phenyl 
group and pyrazole moiety with the enzyme's Arg A17 residue. Strong hydrogen bonding between 9a carbonyl group and the enzyme's Lys A198 residue as well as an additional hydrogen bonding between amidic NH and Val A180 residue, Figure 3. Compound 9a thus exhibited good docking interactions with the active sites of both $P f$-DHFR and Lm-PTR1 enzymes, which confirms the results of the observed antimalarial and antileishmanial activity in biological screening tests.

\section{Conclusions}

The aim of the present study was the discovery of new antileishmanial and/or antimalarial agents. Pyrazole derivatives $9 \mathbf{a}$ and $\mathbf{9 b}$ synthesized in this study were found to be potent dual antimalarial antileishmanial agents. They exhibited comparable antimalarial activity to the standard drug chloroquine and higher activity than the antileishmanial drug miltefosine. Additionally, compounds $\mathbf{4 a}$ and $\mathbf{4 b}$ exhibited significant antileishmanial activity compared to miltefosine. These compounds were found to be well-tolerated and non-toxic in mice exposed acutely to high doses, both orally and intraperitoneally. Molecular docking of compound 9a revealed strong binding interactions with malarial $P f$-DHFR active site as well as $L m$-PTR1 active site. It may be concluded that compounds $\mathbf{9 a}$ and $\mathbf{9 b}$ would represent a valuable scaffold for the design of a new class of dual-acting antileishmanial antimalarial agents that would be worthy of further investigation and derivatization.

\section{Funding}

This research received no external funding.

\section{Acknowledgments}

The authors are highly grateful to Prof. Ahmed Farghaly, Faculty of Pharmacy, Alexandria University, Alexandria, Egypt, for his kind donation of some chemicals.

\section{Conflicts of Interest}

The authors declare no conflict of interest.

\section{References}

1. WHO. WHO fact sheet Leishmaniasis. 2021. Available online: https://www.who.int/news-room/factsheets/detail/leishmaniasis. (accessed on 7th July 2021)

2. WHO. World Malaria Report 2020. Geneva: World Health Organization; 2020. Available online: https://www.mmv.org/sites/default/files/uploads/docs/publications/World_Malaria_Report_2020.pdf. (accessed on 7th July 2021)

3. Alven, S.; Aderibigbe, B.A. Nanoparticles Formulations of Artimisinin and Derivatives as Potential Therapeutics for the Treatment of Cancer, Leishmaniasis and Malaria. Pharmaceutics 2020, 12, 748, https://doi.org/10.3390/pharmaceutics12080748.

4. Fontinha, D.; Moules, I.; Prudêncio, M. Repurposing Drugs to Fight Hepatic Malaria Parasites. Molecules 2020, 25, 3409, https://doi.org/10.3390/molecules25153409.

5. Wicht, K.J.; Mok, S.; Fidock, D.A. Molecular Mechanisms of Drug Resistance in Plasmodium falciparum Malaria. Anпu Rev Microbiol. 2020, 74, 431-454, https://doi.org/10.1146/annurev-micro-020518-115546.

6. Hanboonkunupakarn, B.; White, N.J. Advances and roadblocks in the treatment of malaria. Br J Clin Pharmacol. 2020, https://doi.org/10.1111/bcp.14474. Epub ahead of print.

7. Roatt, B.M.; de Oliveira Cardoso, J.M.; De Brito, R.C.F.; Coura-Vital, W.; de Oliveira Aguiar-Soares, R.D.; Reis, A.B. Recent advances and new strategies on leishmaniasis treatment. Appl. Microbiol. Biotenchol. 2020, 104, 8965-8977, https://doi.org/10.1007/s00253-020-10856-w. 
8. Pinart, M.; Rueda, J.R.; Romero, G.A.; Pinzón-Flórez, C.E.; Osorio-Arango, K.; Silveira Maia-Elkhoury, A.N.; Reveiz, L.; Elias, V.M.; Tweed, J.A. Interventions for American cutaneous and mucocutaneous leishmaniasis. Cochrane Database Syst. Rev. 2020, 8, $\quad$ CD004834, https://doi.org/10.1002/14651858.CD004834.pub3.

9. Machín, L.; Nápoles, R.; Gille, L.; Monzote, L. Leishmania amazonensis response to artemisinin and derivatives. Parasitol Int. 2021, 80, 102218, https://doi.org/10.1016/j.parint.2020.102218.

10. Iwaloye, O.; Elekofehinti, O.O.; Kikiowo, B.; Fadipe, T.M.; Akinjiyan, M.O.; Ariyo, E.O.; Aiyeku, O.O.; Adewumi, N.A. Discovery of Traditional Chinese Medicine Derived Compounds as Wild Type and Mutant Plasmodium falciparum Dihydrofolate Reductase Inhibitors: Induced Fit Docking and ADME Studies. Curr. Drug Discov. Technol. 2021, 18, 554-569, https://doi.org/10.2174/1570163817999200729122753.

11. Kamchonwongpaisan, S.; Charoensetakul, N.; Srisuwannaket, C.; Taweechai, S.; Rattanajak, R.; Vanichtanankul, J.; Vitsupakorn, D.; Arwon, U.; Thongpanchang, C.; Tarnchompoo, B.; Vilaivan, T.; Yuthavong, Y. Flexible diaminodihydrotriazine inhibitors of Plasmodium falciparum dihydrofolate reductase: Binding strengths, modes of binding and their antimalarial activities. Eur. J. Med. Chem. 2020, 195, 112263, https://doi.org/10.1016/j.ejmech.2020.112263.

12. Bilsland, E.; van Vliet, L.; Williams, K.; Feltham, J.; Carrasco, M.P.; Fotoran, W.L.; Cubillos, E.F.G.; Wunderlich, G.; Grøtli, M.; Hollfelder, F.; Jackson, V.; King, R.D.; Oliver, S.G. Plasmodium dihydrofolate reductase is a second enzyme target for the antimalarial action of triclosan. Sci. Rep. 2018, 8,1038, https://doi.org/10.1038/s41598-018-19549-X.

13. Hoarau, M.; Vanichtanankul, J.; Srimongkolpithak, N.; Vitsupakorn, D.; Yuthavong, Y.; Kamchonwongpaisan, S. Discovery of new non-pyrimidine scaffolds as Plasmodium falciparum DHFR inhibitors by fragment-based screening. J. Enzyme Inhib. Med. Chem. 2021, 36, 198-206, https://doi.org/10.1080/14756366.2020.1854244.

14. Neri, F.S.M.; Júnior, D.B.C.; Froes, T.Q.; da Silva, P.B.G.; do Egito, M.S.; Moreira, P.O.L.; de Pilla Varotti, F.; Castilho, M.S.; Teixeira-Neto, R.G.; de Albuquerque, J.F.C.; Leite, F.H.A. Antileishmanial activity evaluation of thiazolidine-2,4-dione against Leishmania infantum and Leishmania braziliensis. Parasitol. Res. 2020, 119, 2263-2274, https://doi.org/10.1007/s00436-020-06706-3.

15. Eldehna, W.M.; Almahli, H.; Ibrahim, T.M.; Fares, M.; Al-Warhi, T.; Boeckler, F.M.; Bekhit, A.A.; AbdelAziz, H.A. Synthesis, in vitro biological evaluation and in silico studies of certain arylnicotinic acids conjugated with aryl (thio)semicarbazides as a novel class of anti-leishmanial agents. Eur. J. Med. Chem. 2019, 179, 335-346, https://doi.org/10.1016/j.ejmech.2019.06.051.

16. Istanbullu, H.; Bayraktar, G.; Akbaba, H.; Cavus, I.; Coban, G.; Debelec Butuner, B.; Kilimcioglu, A.A.; Ozbilgin, A.; Alptuzun, V.; Erciyas, E. Design, synthesis, and in vitro biological evaluation of novel thiazolopyrimidine derivatives as antileishmanial compounds. Arch. Pharm. (Weinheim) 2020, 353, e1900325, https://doi.org/10.1002/ardp.201900325.

17. Gupta, O.; Pradhan, T.; Bhatia, R.; Monga, V. Recent advancements in anti-leishmanial research: Synthetic strategies and structural activity relationships. Eur. J. Med. Chem. 2021, 223, 113606, https://doi.org/10.1016/j.ejmech.2021.113606.

18. Bekhit, A.A.; Saudi, M.N.; Hassan, A.M.; Fahmy, S.M.; Ibrahim, T.M.; Ghareeb, D.; El-Seidy, A.M.; AlQallaf, S.M.; Habib, H.J.; Bekhit, A.E.A. Synthesis, molecular modeling and biological screening of some pyrazole derivatives as antileishmanial agents. Future Med. Chem. 2018, 10, 2325-2344, https://doi.org/10.4155/fmc-2018-0058.

19. Bekhit, A.A.; Hassan, A.M.; Abd El Razik, H.A.; El-Miligy, M.M.M.; El-Agroudy, E.J.; Bekhit, A.E.D. New heterocyclic hybrids of pyrazole and its bioisosteres: Design, synthesis and biological evaluation as dual acting antimalarial-antileishmanial agents. Eur. J. Med. Chem. 2015, 94, 30-44, https://doi.org/10.1016/j.ejmech.2015.02.038.

20. Verma, R.; Verma, S.K.; Rakesh, K.P.; Girish, Y.R.; Ashrafizadeh, M.; Sharath Kumar, K.S.; Rangappa, K.S. Pyrazole-based analogs as potential antibacterial agents against methicillin-resistance staphylococcus aureus (MRSA) and its SAR elucidation. Eur. J. Med. Chem. 2021, 212, 113134, https://doi.org/10.1016/j.ejmech.2020.113134.

21. Nayak, S.G.; Poojary, B.; Kamat, V. Novel pyrazole-clubbed thiophene derivatives via Gewald synthesis as antibacterial and anti-inflammatory agents. Arch. Pharm. (Weinheim) 2020, 353, e2000103, https://doi.org/10.1002/ardp.202000103.

22. Sharma, S.; Bhatia, V. Appraisal of the Role of In silico Methods in Pyrazole Based Drug Design. Mini. Rev. Med. Chem. 2021, 21, 204-216, https://doi.org/10.2174/1389557520666200901184146.

23. Zhang, B.; Hu, X.T.; Zhou, K.M.; Yang, Y.S.; Zhu, H.L. Discovery of novel aminophosphonate derivatives containing pyrazole moiety as potential selective COX-2 inhibitors. Bioorg. Chem. 2020, 102, 104096, https://doi.org/10.1016/j.bioorg.2020.104096. 
24. Al-Soliemy, A.M.; Sabour, R.; Farghaly, T.A. Pyrazoles and fused pyrimidines: Synthesis, structure elucidation, antitubercular activity and molecular docking study. Med. Chem. 2021, https://doi.org/10.2174/1573406417666210324131951. Epub ahead of print.

25. Abdulla Afsina, C.M.; Aneeja, T.; Neetha, M.; Anilkumar, G. Recent Advances in the Synthesis of Pyrazole Derivatives. Curr. Org. Synth. 2021, 18, 197-213, https://doi.org/10.2174/1570179417666201109151036.

26. Fidock, D.A.; Rosenthal, P.J.; Croft, S.L.; Brun, R.; Nwaka, S. Antimalarial drug discovery: efficacy model for compound screening. Nat. Rev. Drug Discov. 2004, 3, 509-520, https://doi.org/10.1038/nrd1416.

27. Mikus, J.; Steverding, D. A simple colorimetric method to screen drug cytotoxicity against Leishmania using the dye Alamar Blue. Parasitol. Int. 2000, 48, 265-269, https://doi.org/10.1016/s1383-5769(99)00020-3.

28. Bekhit, A.A.; Baraka, A.M. Novel milrinone analogs of pyridine-3-carbonitrile derivatives as promising cardiotonic agents. Eur. J. Med. Chem. 2005, 40, 1405-1413, https://doi.org/10.1016/j.ejmech.2005.06.005.

29. Bekhit, A.A.; Hymete, A.; Asfaw, H.; Bekhit, A.E.A. Synthesis and biological evaluation of some pyrazole derivatives as antimalarial agents. Arch. Pharm. 2012, 345, 147-54, https://doi.org/10.1002/ardp.201100078.

30. Habib, N.S.; Farghaly, A.M.; Ashour, F.A.; Bekhiy A.A.; Abd El Razik, H.A.; Abd El Azeim, T. Synthesis of some triazolophthalazine derivatives for their anti-inflammatory and antimicrobial activities. Arch. Pharm. Chem. Life Sci. 2011, 344, 530-542, https://doi.org/10.1002/ardp.201100053.

31. Bekhit, A.A.; Fahmy, H.T. Design and synthesis of some substituted 1H-pyrazolyl-oxazolidines or 1Hpyrazolyl-thiazolidines as anti-inflammatory-antimicrobial agents. Arch. Pharm. Chem. Life. Sci. 2003, 336, 111-118, https://doi.org/10.1002/ardp.200390007.

32. Molecular Operating Environment (MOE). Version 2008, Chemical Computing Group, Inc Montreal, Canada: http://www.chemcomp.com.

33. Farghaly, A. M.; Bekhit, A.A.; Park, J. Y. Design and synthesis of some Oxadiazolyl, Thiadiazolyl, Thiazolidinyl and Thiazolyl derivatives of 1H-Pyrazole as anti-inflammatory antimicrobial agents. Arch. Pharm. Chem. Life. Sci. 2000, 333, 53-57, doi: 10.1002/(sici)1521-4184(200002)333:2/3<53::aidardp53>3.0.co;2-e.

34. Faggiani, R.; Howard-Lock, H.E.; Lock, C.J.L.; Orgias, R. 2R,4S-2-(2'-methyl-3'-hydroxy-5'hydroxymethylenepyridine-C4')- 5,5-dimethylthiazolidine-4-carboxylic acid, the product of the reaction of D-penicillamine and vitamin B6. Can. J. Chem. 1991, 69, 1-7, https://doi.org/10.1139/v91-001. 